\title{
Trabajo, género y clase en Au Bonheur des dames de Émile Zola
}

Romina Denisse Cutuli

rominacutuli@mdp.edu.ar

Facultad de Ciencias Económicas y Sociales

Universidad Nacional de Mar del Plata

Calle Deán Funes 3350, 2. piso, oficina 2

7600, Mar del Plata, Provincia de Buenos Aires

Resum: En aquest article proposo una lectura d'Au Bonheur des dames d'Émile Zola, atenta a las representacions construïdes al voltant del progrés i les transformacions en la la vida urbana europea decimonònica. Hi desenvoluparé un estudi dels personatges, els vincles que creen, de manera que la botiga, més que com un mer escenari, és un gran protagonista, cor de la metamorfosi de la vida social i material. Hi trobem els qui tenen èxit i els exclosos, un espai per a la «carrera oberta al talent», no només per al burgès, sinó també per als treballadors del comerç que, a diferència dels industrials, podien assolir l'èxit juntament amb el patró. Per acabar, faig una breu referència a la sèrie The Paradise, com una reescriptura de la novel.la de Zola al segle XxI.

PARAules ClAU: Zola, representacions, burgesia, treball/consum, classe/gènere.

Work, gender and class in Au Bonheur des dames by Émile Zola АвsтRACT: In this article I propose a reading of Au Bonheur des dames by Émile Zola, attentive to the representations built around progress and transformations in nineteenth-century European urban life. A study of the characters and their associations will be developed, understanding the store as more than a mere stage, but as a great protagonist, the heart of the metamorphosis of social and material life. They are successful and exclusive, spaces for the "career open to talent", not only for the bourgeoisie but also for trade workers who, unlike the industrialists, could achieve success with employers. Finally, I make brief reference to the series The Paradise, as a rewrite in the 2Ist century of Zola's novel.

CUtul, Romina Denisse, «Trabajo, género y clase en Au Bonheur des dames de Émile Zola». Cercles. Revista d'Història Cultural, 24, 13-46. ISSN: 1139-0158. ISSN-e: 1699-7468. DOI: 10.1344/ cercles2021.24.1001. Data de recepció: 5/3/2020. Data d'acceptació: 2/12/2020. 
KEYwORDs: Zola, representations, bourgeoisie, work/consumption, class/ gender.

Resumen: En este artículo propongo una lectura de Au Bonheur des dames de Émile Zola, atenta a las representaciones construidas en torno al progreso y las transformaciones en la vida urbana europea decimonónica. Se desarrollará un estudio de los personajes y los vínculos que crean, entendiendo la tienda, más que como un mero escenario, como una gran protagonista, corazón de la metamorfosis de la vida social y material. Hay exitosos y excluidos, espacio para la "carrera abierta al talento», no solo para el burgués, sino también para los trabajadores de comercio que, a diferencia de los industriales, podían alcanzar el éxito junto al patrón. Finalmente, hago breve referencia a la serie The Paradise, como reescritura en el siglo xxi de la novela de Zola.

PALAbras Clave: Zola, representaciones, burguesía, trabajo/consumo, clase/género. ${ }^{\text {I }}$

N'était-ce pas une création étonnante? Elle bouleversait le marché, elle transformait $\mathrm{Pa}$ ris, car elle était faite de la chair et du sang de la femme.

Émile Zola, Au Bonheur des dames, $1885^{2}$

I La versión preliminar de este artículo se gestó en el marco del seminario de posgrado «El burgués y sus ficciones», impartido por Justo Serna y Encarna García Monerris durante el segundo cuatrimestre de 2018 en la Facultad de Humanidades, Universidad Nacional de Mar del Plata, Argentina. Tanto los intercambios desarrollados durante ese curso como las sugerencias de los evaluadores sobre la primera versión ofrecieron claves de análisis e intertextualidades que no había advertido en la primera redacción. La persistencia de las limitaciones, en un universo tan rico y arduo de abarcar como el de la obra de Zola, es enteramente de mi autoría.

2 Todas las citas en francés de la obra corresponden a Émile ZolA, Au bonheur des dames, La Bibliothèque électronique du Québec, disponible en: https://beq.ebooksgratuits. com/vents/zola-II.pdf (última consulta: I2 de diciembre de 20I8). En todos los casos, se colocará como nota al pie la traducción española, extraída de Émile Zola, El paraíso de las damas, Barcelona, Alba Editorial, libro electrónico, 2012 : «¿No era acaso todo eso un invento sorprendente, que estaba trastocando los negocios y trastocando París porque se amasaba con la carne y la sangre de la mujer?», p. II2. 


\section{Introducción}

En la segunda mitad del siglo xix, una nueva revolución sin chimeneas completaba la gran transformación que había tenido lugar en la industria textil: la masificación del consumo. Los grandes almacenes departamentales condensan una multiplicidad de sentidos sociales, económicos y culturales que emergen en las líneas de $A u$ Bonheur des dames. La modernidad abre sus puertas a un espacio profano de convivencia interclasista. En él se hace carne la ley de Say, a través de esas clientas seducidas por el deseo de productos cuya existencia ni tan siquiera habían soñado. La oferta creaba su propia demanda.

París, la llamada por Balzac «ciudad de las mil novelas», constituye un objeto de problematización de la literatura decimonónica allí gestada, trascendiendo el mero telón de fondo de las tramas narrativas. ${ }^{3}$ Au Bonheur des dames urde la génesis del gran almacén departamental integrada con la espectacular transformación urbana emprendida por Haussmann. ${ }^{4}$ Entre el horror y el esplendor, en ella se cristalizan las expectativas y los temores decimonónicos en torno al progreso. Sus largas páginas de desencuentro amoroso se resuelven en expeditivos párrafos en que felicidad se asimila con normalidad. El matrimonio burgués, el repliegue en el espacio privado y doméstico donde transcurre una cotidianeidad sin sobresaltos, no es tema digno de la literatura decimonónica. El burgués es aburrido, y debe serlo. El homo oeconomicus es un sujeto despojado de pasiones en virtud de la maximización del beneficio, a menos que convierta la maximización del beneficio en su pasión, como sucede con Mouret. Las mujeres,

3 Juan Calatrava Escobar, «Balzac urbanista. El espacio parisino en Ferragus», Revista Proyecto y Ciudad, núm. 2, 20II, pp. 5-22.

4 Jean-Pierre Bernard, Les deux Paris. Les représentations de Paris dans la seconde moitié du XIXe siècle, Seyssel, Champ Vallon, 200I. 
débiles de carácter y sometidas a sus impulsos más primitivos serán en $\mathrm{Au}$ Bonheur des dames la fuente de enriquecimiento inagotable para Mouret, ahora que el consumo se trastoca de necesidad en deseo.

En este ensayo se propone una lectura triangular entre las mujeres, los hombres y la tienda. Al igual que París, Au Bonheur des dames no es un mero escenario. Zola trama historias individuales sobre la transformación social del Segundo Imperio. En sintonía con el programa artístico del naturalismo que él mismo está gestando, realiza un exhaustivo trabajo documental que acompañará a los veinte volúmenes de Les Rougon-Macquart. Esta conception ethnographiques de la novela permite adentrarse en la riqueza de los personajes como sujetos sociales a los que podemos aproximarnos a través de su lectura. Entre las mujeres, se destaca su protagonista, Denise. Aunque no se la describe como bella al comienzo, su imagen se mimetiza con sus virtudes a medida que avanza la historia. Su antagonista es Henriette, prometida de Mouret, dueño de la tienda e interesado en ella como medio de acceso al barón Hartmann, proveedor del capital necesario para su proyecto de expansión de la tienda. Adinerada, presumida, viuda y mayor, compendia los defectos necesarios para realzar las humildes virtudes de Denise. Sus compañeras, Clara y Pauline, despiadada una, poco avispada la otra, refuerzan la síntesis entre bondad e inteligencia de Denisse. Una legión de clientas, unas frágiles de carácter y propensas a endeudarse, otras soberbias, algunas prudentes, caen masivamente en los encantos ofrecidos por la tienda.

Mouret, el propietario e ideólogo de ese prodigio de la modernidad, aporta su encanto personal al éxito de la tienda y viceversa. Su fiel compañero, prudente y temeroso, constituye la contracara necesaria del espíritu arriesgado del epítome del capitalismo que es Mouret. Sabrá este seducir no sólo a sus clientas y a las mujeres con las

5 Henri Mitterrand, Zola, l'histoire et la fiction, París, Presses Universitaires de France, 1990.

Cercles. Revista d'Història Cultural, 24 (2021), 13-46.

ISSN: 1139-0158. e-ISSN: 1699-7468. DOI: 10.1344/cercles2021.24.1001. 
que intima, sino también al barón Hartmann, intermediario imprescindible para concretar sus proyectos.

La tienda es la gran protagonista, puesto que en ningún otro espacio podrían haberse dado esos lazos sociales que devienen en íntimos. La tienda es esplendor y monstruosidad. A la vez propiedad privada y espacio público, trastoca sentidos y fronteras entre lo íntimo-privado-doméstico y lo público-productivo. Las interacciones y tensiones entre los personajes de Au Bonheur des dames sólo son posibles allí, donde la modernidad une aquello que la tradición separaba. $A$ Bonheur des dames es una ventana entreabierta para adentrarnos en la emergencia de estos sujetos disonantes. ${ }^{6}$ Un patrono talentoso, una trabajadora lúcida, un espacio productivo esplendoroso. Lejos de la sordidez de la mina y la fábrica, Zola narra y otorga sentidos a los orígenes de este monstruoso y fastuoso producto del capital que comienza a erigirse a mediados de siglo y reina tras la caída del Segundo Imperio.

\section{Las mujeres de $A u$ Bonheur des dames: trabajo y consumo}

Comencemos con Denise. Una muchacha de pueblo, huérfana y a cargo de sus hermanos menores, llega a la gran ciudad en busca de oportunidades de subsistencia. Un tránsito cada vez más habitual en la época. Un camino que sería solo de ida, en virtud del creciente movimiento migratorio desde el campo hacia la ciudad. ${ }^{7}$ Su pobreza inocultable desentona con el esplendor de la tienda. No es bonita, mas luce una larga cabellera rubia. Como recién llegada, sufre toda clase de hostigamientos por parte de sus compañeras y superiores,

6 En línea con el planteamiento de Luckacs de la forma como un mecanismo de resolución de la disonancia. György Lukács, Teoría de la novela, Madrid, DeBolsillo, 2016.

7 Michelle Perrot, Mi historia de las mujeres, Buenos Aires, FCE, 2008. 
con algunas excepciones que harán soportables las largas jornadas y las privaciones materiales. La vida transcurre casi íntegra dentro de la tienda, lo que pone en vilo la habitual lectura de la separación de los espacios productivo y reproductivo-doméstico en el capitalismo urbano. Los empleados de la tienda no transitan el camino del trabajo a la casa, viven en el trabajo. Las jornadas se prolongan tanto como es posible, dejando apenas tiempo para sostener la vida biológica, de modo que sea factible la jornada del día siguiente. Denise cae rendida cada noche, para luego acicalarse como puede en un cuartucho desproporcionado con las exigencias estéticas del puesto y con el impecable vestido de seda negra que uniforma a las dependientas.

Con todo, el trabajo ofrece un dinamismo y unas oportunidades de movilidad atractivos en contraste con la abulia del trabajo industrial. ${ }^{8}$ Denise descubre la dinámica del comercio y el mundo de infinitas posibilidades que se abre frente a la seducción de la tienda en las clientas. Aprenderá tanto a identificar las expectativas inexplotadas como a despertar deseos desconocidos. Sabrá, también, ampliar el público hacia un segmento novedoso, que viene literalmente de las manos de las mujeres y tendrá espacio propio gracias a su iniciativa: los niños. La buena madre burguesa será juzgada a través de sus obras, y la vestimenta y pulcritud de los niños serán tan prioritarios como sus modales. Los niños serán más que destinatarios indirectos de las maravillas ofrecidas por Au Bonheur des Dames. Cuando la vanidad no es lícita, se apelará al sentimiento maternal, ${ }^{9}$ construcción decimonónica consolidada junto con el niño como sujeto social con características específicas:

8 Ibídem.

9 Yvonne Knibiehler, Historia de las madres y la maternidad en Occidente, Buenos Aires, Nueva Visión, 2000.

Cercles. Revista d'Història Cultural, 24 (2021), 13-46.

ISSN: 1139-0158. e-ISSN: 1699-7468. DOI: 10.1344/cercles2021.24.1001. 
Mais son idée la plus profonde était, chez la femme sans coquetterie, de conquérir la mère par l'enfant; il ne perdait aucune force, spéculait sur tous les sentiments, créait des rayons pour petits garçons et fillettes, arrêtait les mamans au passage, en offrant aux bébés des images et des ballons. ${ }^{\mathrm{IO}}$

Las estrategias publicitarias que tienen a los niños como destinatarios y portadores quedan superadas por la novedosa idea de Denise de incorporar un departamento de niños. Allí, Denise desplegará tanto sus habilidades para la venta como sus virtudes de buena muchacha. Sus días en el departamento de niños recuerdan a Charlotte, la amada de Werther, luciendo su bella cabellera rubia y rodeada de niños que ansiaban su amorosa compañía: ${ }^{\text {II }}$

Denise avait toujours au fond des poches quelques friandises, apaisait les pleurs d'un marmot désespéré de ne pas emporter des culottes rouges, vivait là parmi les petits, comme dans sa famille naturelle, rajeunie elle-même de cette innocence et de cette fraîcheur sans cesse renouvelées autour de ses jupes."

Io Émile Zola, op. cit., p. 49I. Trad: «Pero su idea más alambicada apuntaba a las mujeres que no fueran presumidas, y consistía en conquistar a la madre por mediación del hijo. No desperdiciaba fuerza alguna, no había sentimiento con el que no especulase; creaba departamentos para muchachitos y chiquillas y conseguía que las madres se detuvieran brindando a los pequeños estampas y globos.». Émile Zola, op. cit., p. 304.

II «[...] seis niños, desde dos hasta once años de edad saltaban alrededor de una hermosa joven, de mediana estatura, vestida con una sencilla túnica blanca, adornada con lazos de color de rosa en las mangas y en el pecho. Tenía en la mano un pan moreno, del que a cada uno de los niños cortaba un pedazo proporcionado a su edad y a su apetito. Les repartía las rebanadas con la mayor gracia [...]». Johann Goethe, Werther o Las desventuras del joven Werther, libro electrónico, Valencia, 2008 [I774], p. 42.

I2 Émile Zola, op. cit., pp. 739-740. Trad.: «Denise llevaba siempre en el fondo de los bolsillos algunas golosinas; acallaba el llanto de un pequeño que se desesperaba porque no le habían comprado unos pantalones rojos; vivía entre la gente menuda como si fuera su familia, cada vez más joven entre aquella inocencia y aquella lozanía que se renovaban sin cesar en torno a sus faldas». Émile Zola, op. cit., p. 222. 
La entereza con que había sobrellevado los momentos de mayor carencia material y de maltrato por parte de sus compañeros, la bondad que conservaba y la perspicacia desarrollada como aguda observadora de la dinámica de la tienda, convertían a Denise en una mujer excepcional. Tan alejada de las vanidades burguesas de Henriette, la viuda y prometida de Mouret, como de las mezquindades de Clara y las torpezas de Pauline:

Elle apportait tout ce qu'on trouve de bon chez la femme, le courage, la gaieté, la simplicité ; et, de sa douceur, montait un charme, d'une subtilité pénétrante de parfum. On pouvait ne pas la voir, la coudoyer ainsi que la première venue ; bientôt, le charme agissait avec une force lente, invincible ; on lui appartenait à jamais, si elle daignait sourire. Tout souriait alors dans son visage blanc, ses yeux de pervenche, ses joues et son menton troués de fossettes; tandis que ses lourds cheveux blonds semblaient s'éclairer aussi, d'une beauté royale et conquérante. Il s'avouait vaincu, elle était intelligente comme elle était belle, son intelligence venait du meilleur de son être..$^{13}$

La perdición de las mujeres consumidoras, la resignación o la mezquindad de las trabajadoras, la vanidad de Henriette, intensifican la excepcionalidad de la heroína. Las virtudes de Denise se refuerzan mediante dos artilugios narrativos. Florece en el barro de la pobreza, del sufrimiento, las privaciones y las obligaciones, como

I3 Émile Zola, op. cit., p. 694. Trad.: «Poseía todo lo bueno que existe en una mujer: el coraje, la alegría, la sencillez; y de su dulzura brotaba un encanto tan penetrante y sutil como un perfume. Era imposible no fijarse en ella, comportarse con ella como con cualquier otra mujer; el mágico encanto obraba enseguida con fuerza lenta e invencible; y aquel a quien se dignaba sonreír le pertenecía ya para siempre. Todo sonreía en su rostro de blanco cutis: los ojos de vincapervinca, las mejillas y el mentón marcados de hoyuelos: y hasta el abundante pelo rubio parecía iluminarse con una hermosura regia y victoriosa. Mouret admitía la propia derrota: Denise era tan inteligente como hermosa, su inteligencia provenía de lo mejor de su ser». Émile Zola, op. cit., p. 428.

Cercles. Revista d'Història Cultural, 24 (2021), 13-46.

ISSN: 1139-0158. e-ISSN: 1699-7468. DOI: 10.1344/cercles2021.24.1001. 
hermana mayor huérfana a cargo de los menores. Resiste con grandeza y creatividad los embates que pierden a las otras:

Cette vie de chien battu rendait mauvaises les meilleures: et le triste défilé commençait. ${ }^{\text {I4 }}$

El trabajo desgasta, las necesidades corrompen. Pauline, uno de los pocos rostros amables con que se encuentra Denise en el entorno hostil del nuevo empleo, insiste en la inevitabilidad de acabar con un querido que cuando menos le compre unos zapatos. Clara hace lo que sea con tal de obtener alguna comisión extra y no escatima dotes de seducción a cambio de favores materiales. La señora Aurelie, encargada del departamento de ropa de confección, exigente y arbitraria, hostiga a Denise con órdenes injustas, favoritismos, dando a entender que no es posible sobrevivir y crecer en ese lugar sin una maldad ambiciosa e ilimitada.

El trabajo como espacio de corrupción y degradación de las mujeres constituye un tópico cuyos ecos trascienden hasta las primeras regulaciones del mercado de trabajo. Las mujeres enferman, la humanidad degenera. Las descripciones acerca de la degradación obrera se convierten en un lugar común al calor de los debates políticos sobre la necesidad de legislar sobre la salud obrera. ${ }^{15}$ La discriminación a las mujeres casadas y a las madres, con un emotivo giro hacia el final de la historia en la figura de Pauline, es todo lo que el capital aporta para proteger la reproducción. Tras la exclusión quedan los ecos de los años de trabajo insalubre, la imposibilidad de asegurar la subsistencia. El trabajo expone a vulnerabilidades que repercuten en

I4 Émile Zola, op. cit., p. 74I. Trad.: «Aquella vida de perro apaleado volvía malas a las mejores: y el triste desfile se repetía una y otra vez». Émile Zola, op. cit., p. 455.

is Marie-Helene Zylberberg-Hocquard, «Historia y división sexual del trabajo. La obrera», en H. Hirata y D. Kergoat, La división sexual del trabajo. Permanencia y cambio, Buenos Aires, Trabajo y Sociedad, 1997. 
las marchitas biografías sobre las que Denise, cuando adquiere suficiente influencia, pretende arrojar algo de luz.

Si su inteligencia y templanza la distinguen de sus compañeras, su sencillez y humildad trazan un abismo con las clientas. Perdidas en el encanto del consumo, seducidas por la inagotable oferta de novedades que pronto trastocaban de deseos a necesidades, dilapidan el ingreso familiar e incluso algunas mancillan su honor escondiendo bajo sus atavíos más caprichos de los que sus monederos pueden proporcionarles. Quizás no sería exagerado afirmar que Zola dedica muchas más líneas al juego de seducción entre las clientas y los vendedores, los productos y el propio Mouret, como artífice de las estratagemas, que a la historia de amor central en la novela. Sólo en los últimos capítulos se intensifican los lazos de afectividad entre Denise y Mouret, los simultáneos lamentos, ella por no ceder, y él por no poseerla. La seducción irresistible del consumo, tanto en las habilidades de Mouret para la conquista del mercado como en la debilidad de las mujeres que caen en ella, constituye un elemento central en la trama. Ahogadas en las efímeras satisfacciones proporcionadas por las sedas, los guantes, los perfumes, los sombreros, los bordados, las mujeres ven cumplidas en la tienda, el paseo y la compra las promesas que el «final feliz» del matrimonio burgués no es capaz de satisfacer.

La democratización del lujo, como lo llamó Zola, proporciona, además, identidades nacidas de las semejanzas visuales entre las crecientes clases medias y la aristocracia decadente. En Au Bonheur des Dames, tal democratización es solo comprar seda a precio de ganga. Visitar la tienda constituye una experiencia de acceso al lujo. Los espacios amplios, decorados, las comodidades y la belleza de la vivienda aristocrática se presentan ahora en un lugar habilitado para explorar con todos los sentidos. Terciopelo, ascensores, galerías de arte. Esa ventana a la vida suntuaria brinda también una oportunidad inédita de desearla, envidiarla y emularla a cualquier costo. La imitación borra las fronteras y las mujeres más adineradas procuran 
en vano mantener consumos distintivos, refinan la excentricidad, aunque sea pagando más caro por la misma cosa:

—Mon Dieu! oui, répondit Henriette, Sauveur est très chère, mais il n'y a qu'elle à Paris qui sache faire un corsage... Et puis, M. Mouret a beau dire, elle a les plus jolis dessins, des dessins qu'on ne voit nulle part. Moi, je ne peux pas souffrir de retrouver ma robe sur les épaules de toutes les femmes. ${ }^{16}$

La popularización hacia las capas medias de consumos antaño suntuarios, hija tanto de la producción en masa como de la mejora relativa de los salarios reales en la segunda mitad del siglo XIX, se ve resistida por aquellos sectores que hasta hace pocas décadas han preservado el privilegio exclusivo de consumir más allá de la mera subsistencia. Mientras los recién llegados al tren del consumo resignifican y hacen suyos los lujos y las vanidades, las damas de esa aristocracia decadente aceleran la caída con su desmedida irracionalidad económica. El esfuerzo se ve frustrado una y otra vez por las estrategias comerciales promotoras de una moda que se impone a costa de diluir la originalidad. La publicidad y la producción masiva se apropian de la estética aristocrática y la convierten en moda burguesa. Más temprano que tarde, las damas como Henriette deben resignarse a llevar todas el mismo vestido. La novela de Zola expone asimismo el sentimiento de novedad experimentado por esas primeras generaciones de mujeres que transitan el espacio público y viven en carne propia los placeres y desbordes del consumo masivo. Con

I6 Émile Zola, op. cit., p. I70. Trad.: «La verdad es que sí —contestó Henriette-. Sauveur es muy cara, pero es la única, en todo París, que sabe hacer las blusas como es debido... Y por mucho que diga el señor Mouret, tiene los estampados más bonitos, unos estampados que no se ven en ninguna otra parte. No puedo soportar que todas las mujeres lleven el mismo vestido que yo». Émile ZolA, op. cit., p. 107. 
ellos surge también la convivencia con la insatisfacción por los infinitos placeres que el mercado ofrece y no es posible obtener:

Elle avait repris l'éventail, l'examinait de nouveau avec sa fille Blanche ; et, sur sa grande face régulière, dans ses larges yeux dormants, montait l'envie contenue et désespérée du caprice qu'elle ne pourrait contenter. ${ }^{17}$

Empleadas mezquinas, consumidoras irracionales, aristócratas vanidosas. El desfile de imperfecciones femeninas eleva a lo más alto las virtudes de Denise. La belleza de espíritu de Denise procura la conversión del interés en justicia. Su movilidad social constituye una historia con final feliz por su trascendencia de la individualidad, su capacidad de convertir el mundo - la tienda - en un lugar menos cruel y más justo. El temor que puso freno a la ambición desmedida habría sido la construcción del pecado de la avaricia. ${ }^{18}$ Sin palos en las aspas del "molino satánico», ¿q ¿qué límite habría para consumir las energías vitales de las personas como ellas mismas - u otras - lo hacen con ese desfile de vacuidades que ahora se les presentan como imprescindibles? Denise logra introducir mejoras en las condiciones de trabajo aludiendo a la conveniencia de la máquina bien aceitada, a la racionalidad económica de la prevención por encima de la reparación:

Était-ce humain, était-ce juste, cette consommation effroyable de chair que les grands magasins faisaient chaque année? Et elle plaidait la cause des rouages de la machine, non par des raisons sentimentales, mais par des arguments tirés de l'intérêt même des patrons.

I7 Émile Zola, op. cit., p. I72. Trad.: «Había vuelto a coger el abanico para examinarlo, junto con su hija Blanche; y en el rostro carnoso de rasgos regulares, en los ojos grandes y soñolientos, iba creciendo un deseo refrenado y ansioso por aquel capricho que no podría nunca satisfacer». Émile Zola, op. cit., p. Iıo.

I8 Albert Hirschman, Las pasiones y los intereses, México, FCE, 1978.

I9 Karl Polanyi, La gran transformación, Buenos Aires, FCE, 2013 [I958].

Cercles. Revista d'Història Cultural, 24 (2021), 13-46.

ISSN: 1139-0158. e-ISSN: 1699-7468. DOI: 10.1344/cercles2021.24.1001. 
[...] Il [Mouret] l'accusait de socialisme [...] il l'écoutait en la plaisantant, le sort des vendeurs était amélioré peu à peu, on remplaçait les renvois en masse par un système de congés accordés aux mortessaisons, enfin on allait créer une caisse de secours mutuels, qui mettrait les employés à l'abri des chômages forcés, et leur assurerait une retraite. $^{20}$

Zola dedica largas líneas a explicar la diversidad de actividades culturales, el cuidado de la salud y el bienestar que, de la mano de Denise, hacen de Au Bonheur des Dames un lugar seguro y agradable también para sus empleados. En el personaje de Denise se condensa la transición de clase a movimiento obrero, en la figura de sujetos con identidad obrera que acceden a espacios de poder apropiados en el proceso de democratización. ${ }^{21}$ Aun cuando se sugiriera que, en buena parte, Mouret acabara por ceder a las demandas en virtud de su devoción personal hacia ella, los logros obtenidos rinden tributo a una identidad de clase que Denise no pierde. En su voz «encore frémissante des maux endurés». Lejos del clásico cuento de hadas, Denise «ne s'en tenait pas à vouloir panser les plaies vives dont elle avait saigné». ${ }^{22}$ No le basta la solución individual. Ahí radica quizás, lo extraordinario del final feliz en $A u$ Bonheur des dames.

20 Émile Zola, op. cit., pp. 74I-742. Trad.: «¿Era humano y justo aquel atroz consumo de carne anual de los grandes almacenes? Denise abogaba por los engranajes de la maquinaria; no alegaba para ello razones sentimentales, sino argumentos tomados del propio interés de los patronos. [...] [Mouret] La acusaba de socialista[...] le hacía caso, aunque le gastase bromas, y la suerte de los dependientes iba mejorando poco a poco. En vez de los despidos en masa, se fue organizando un sistema de permisos durante las temporadas bajas; y, por fin, iba a fundarse muy pronto una caja de solidaridad que pondría a los empleados al amparo del paro forzoso y les garantizaría una pensión». Émile Zola, op. cit., pp. 456-57.

2I Eric Новsваwм, La era del Imperio, Barcelona, Crítica, I987.

22 Émile ZOLA, Au bonheur.., ob. cit., p. 742-743. Tr.: «vibraban los males que había soportado" y "no se conformaba con curar las llagas abiertas que ella había padecido". Émile ZOLA, op. cit., p. 456. 


\section{Los varones de Au Bonheur des dames: el burgués imaginario y otros personajes}

Mouret es el epítome del homo oeconomicus, acaso más prolijo y acabado que el amado por los economistas clásicos Robinson Crusoe. Aunque menos explorado y citado como representación del burgués, Mouret sintetiza los valores de la burguesía decimonónica. ${ }^{23} \mathrm{Al}$ igual que el inspirador de la historia, Aristide Bouciacaut, es innovador, creativo, arriesgado, seductor, inconformista. Su pasión e intuición siempre acertadas constituyen la clave del triunfo en plena "carrera abierta al talento». ${ }^{24}$ Sus virtudes brillan al borde de la inverosimilitud. Todas sus ideas son un éxito. La pasión puesta en la vida pública y la frialdad en la vida privada, expresada con particular intensidad en su indiferencia hacia Henriette, expresan el ideal de hombre decimonónico. El dinero como éxito y el éxito como vocación, mutación casi contemporánea a Weber cuando se interroga acerca de la construcción de este valor, constituyen la esencia del protagonista. La noción smithiana del interés como motor de la vida social queda a horcajadas entre la interpretación y el mandato. En este sentido, la oda al progreso que es Au Bonheur des dames construye a través de Mouret un ideal masculino excepcional e incompleto en los sujetos históricos de carne y hueso. ${ }^{25}$ Ese burgués cuya vida, a decir de Schumpeter, estaba condenada a carecer de toda existencia heroica. ${ }^{26}$

Así como la virtud de Denise resplandece radiante en contraste con las imperfecciones de los otros personajes femeninos, el talento

23 Franco Moretti, El burgués. Entre la historia y la literatura, México, FCE, 2014.

24 Eric Hobsbawm, La era de la Revolución, Barcelona, Crítica, 2007.

25 Raffaele Romanelli, «Borghesia/Burgetum/Bourgeoise. Itinerarios europeos de un concepto», en R. Romanelli, J. Serna y A. Pons, A qué llamamos burguesía, Valencia, Episteme, 1997, pp. I-24.

26 Joseph Schumpeter, Capitalismo, socialismo y democracia, Barcelona, Página Indómita, 2010 .

Cercles. Revista d'Història Cultural, 24 (2021), 13-46.

ISSN: 1139-0158. e-ISSN: 1699-7468. DOI: 10.1344/cercles2021.24.1001. 
de Mouret brilla con mayor intensidad comparado con la opacidad de colaboradores, especuladores o comerciantes anticuados. Su amigo y colaborador Bourduncle, como un Watson fiel y sencillo, se muestra siempre preocupado por el bienestar de su patrón y tiene a mano consejos prudentes que Mouret jamás sigue. Jouve, entre las sombras, ojos del amo allí donde no puede estar, oscila entre la fidelidad y la alcahuetería, descubriendo incluso más delitos de los que hay, empezando por los de Denise. El barón Hartmann, frío y especulador, con el aplomo de quien ha heredado fortuna, procura sostenerla y aumentarla con racionalidad, sin entregar sus emociones a ninguna empresa. Tan escaso es su compromiso que al mismo tiempo invierte en Au Bonheur des Dames y en la que ha surgido como su principal competidora. Vallagnosc, antiguo compañero de estudios, se marchita en una oficina pública a cambio de un salario mediocre. Con él, Mouret se desquita del desprecio y los resquemores que aún pesan sobre los que amasan fortuna en el comercio, y desde abajo. Se da incluso el gusto de echarle en cara que cualquiera de sus dependientes gana más que él con su título de abogado. Sin embargo, el mayor brillo resplandece en torno a la polvorienta oscuridad de los comerciantes decadentes:

[...] La boutique gardait son odeur de vieux, son demijour, où tout l'ancien commerce, bonhomme et simple, semblait pleurer d'abandon. ${ }^{27}$

Viejos como sus comercios, incapaces de competir con la gran escala, la variedad y el esplendor de los grandes almacenes, malviven entre la depresión y el rencor hacia esa clase de inmorales que se ha saltado las reglas del negocio. Continuando con la lectura de Zola, concluiremos que los sujetos como Mouret están redefiniendo las reglas.

27 Émile Zola, op. cit., p. 34. Trad.: «En la tienda seguía habiendo un olor a viejo y una semipenumbra que eran como el llanto con que penaba por su abandono todo el comercio tradicional, bonachón y sencillo». Émile Zola, op. cit., p. 23. 
Sabemos que Mouret ha amasado su fortuna con una combinación de talento y matrimonio de conveniencia sobre el que se sugiere más de lo que se explica, al menos en esta historia. ${ }^{28} \mathrm{Su}$ pasado como dependiente, aunque no lo convierte en un patrón indulgente, sí lo lleva a que podamos identificar líneas de continuidad antes que antinomias entre él y los dependientes. Es un "amo trabajador». ${ }^{29}$ Espera que su trayectoria sea la inspiración de los empleados. Como el perfecto modelo del crecimiento que no conoce límites, espera de los vendedores la misma ambición, la misma astucia, la misma capacidad de seducción. Promueve la competencia y ofrece reconocimientos monetarios y simbólicos a quienes desarrollen con mayor destreza el arte de vender, tiene las cualidades de un líder. ${ }^{30}$ Ello no llevará a eliminar todo rastro de mediocridad de la vida de los dependientes, que «ils se battaient pour l'argent du lundi au samedi, puis ils mangeaient tout le dimanche». ${ }^{35}$ Son, a la postre, versiones empequeñecidas del hortera que reina en París.

Fiel al forzado binarismo con que se construyen los roles de género en la sociedad burguesa decimonónica, Mouret es, como decíamos al comienzo de este apartado, todo lo que el burgués debe ser. Tan acertado y exitoso que raya en lo inverosímil, su descripción se completa en interacción con las mujeres. A ellas les deja la debilidad de las pasiones, él se reserva la racionalidad, el cálculo, la previsión. Ha construido un puente entre la seducción y la publicidad, y conoce tan bien las debilidades femeninas que desarrolla a la perfección las artes de la conquista, tanto personal como comercial. El insípido

28 Dentro de la serie de novelas Les Rougon-Macquart, Au bonheur des dames está precedida por Octavio. Ahí se apuntan y sugieren detalles biográficos sobre el ascenso de Mouret.

29 Franco Moretti, op. cit.

30 Brian Nelson, Zola and the bourgeoise. A study of themes and techniques in les Rougon-Macquart. Londres, Macmillan, 1983.

3I Émile Zola, op. cit., p. 202. Trad.: «luchaban por el dinero de lunes a sábado y se gastaban todas las ganancias el domingo». Émile Zola, op. cit., p. I27.

Cercles. Revista d'Història Cultural, 24 (2021), 13-46.

ISSN: 1139-0158. e-ISSN: 1699-7468. DOI: 10.1344/cercles2021.24.1001. 
Bourdoncle no comprende que "le côté fille du succès, Paris se donnant dans un baiser au plus hardi». ${ }^{32}$ "J'ai la femme, je me fiche du reste ! dit-il dans un aveu brutal, que la passion lui arracha.»" Ciudad mujer, mujer clienta. La doble apropiación de las mujeres y de la ciudad se cristaliza en la personificación de esta última y es susceptible de integrarse en un sistema metafórico que transita los veinte volúmenes de Les Rougon-Macquart. ${ }^{34}$

Sin embargo, para ser un conquistador imparable existe una condición sine qua non, el lugar común archiconocido: el donjuán pierde su eficacia si muta de conquistador a conquistado. Bourdoncle, aunque incapaz de encarnar esas habilidades, parece comprender bien cómo funcionan y le aterra que el encanto se desvanezca si Mouret, en manos de Denise, se transmutara en un «varón domado», parafraseando el exitoso y controvertido mito de Vilar: ${ }^{35}$

C'était, chez lui, comme chez Bourdoncle, une superstition, que le directeur d'une grande maison de nouveautés devait être célibataire, s'il voulait garder sa royauté de mâle sur les désirs épandus de son peuple de clientes : une femme introduite changeait l'air, chassait les autres, en apportant son odeur. ${ }^{36}$

32 Émile Zola, op. cit., p. 72. Trad.: «que el éxito tiene visos de mujerzuela y que París se entrega, en un beso, al más atrevido». Émile Zola, op. cit., p. 49.

33 Émile Zola, op. cit., p. ı6o. Trad.: «jSi las mujeres son mías, lo demás me importa un comino! —exclamó en un brutal arranque de sinceridad». Émile Zola, op. cit., p. IO2.

34 Maarten van BuUren, De la métaphore au mythe. Les Rougon-Macquart d'Émile Zola, Katholieke Universiteit te Nijmegen, Países Bajos, 1985.

35 Esther VIlar, El varón domado, Buenos Aires, Grijalbo, 1973.

36 Émile Zola, op. cit., p. 839. Trad.: «Tanto él como Bourdoncle tenían la supersticiosa creencia de que el director de unos grandes almacenes de novedades tenía que ser soltero si aspiraba a conservar su regio dominio del varón sobre los deseos desfogados de sus clientes y súbditas: la interposición de una mujer modificaba el entorno y su aroma expulsaba a las demás». Émile Zola, op. cit., p. 516. 
Sin embargo, al verlo atribulado, en la tensión entre el éxito público y el sufrimiento privado, ante la imposibilidad de ahogar las pasiones que Denise le despierta, el mismo Bourdoncle promoverá la unión. Sólo la excepcional Denise podría tal vez, en lugar de romper el hechizo, devolverlo al mundo en una versión mejorada. Como el matrimonio Bouciacaut, juntos podrían hacer de Au Bonheur des dames una ventana al siglo $\mathrm{xx}$.

\section{Au Bonheur des dames. Escenario y protagonista}

Como he adelantado al comienzo, el gran almacén aparece, ya desde su título, con un rol protagónico sin parangón en otras novelas del autor. Germinalse refiere a un proceso, Naná, a una mujer, El vientre de París, también al espacio, pero con un carácter metafórico. La taberna es genérico. Au Bonheur des dames es nombre propio, a la vez literalidad y metáfora. Desde las descripciones del esplendor urbano hasta la exhaustividad de la escala social cristalizada en cada uno de sus personajes, esta novela rinde tributo a lo que Benjamin denominó literatura panorámica, ${ }^{37}$ aunque despojada ya de la fisiología ingenua que la había visto nacer..$^{38} A u$ Bonheur des dames, como parte de la historia más extensa y panorámica que se trama en la serie Les Rougon-Macquart, se adentra en cada sutileza de esta transformación social, económica, cultural y fisonómica de la París del Segundo Imperio. ${ }^{39}$ Permite ver cada detalle del árbol, sin que este llegue nunca a tapar el bosque.

El gran almacén se yergue como templo pagano y nuevo espacio central, convocante, de la vida urbana, en especial la femenina. A di-

37 Walter Benjamin, El libro de los pasajes, Madrid, Akal. 2005, p. 40.

38 Walter Benjamin, El París de Baudelaire, Buenos Aires, Eterna Cadencia, 2012.

39 Jean-Pierre Bernard, op. cit. 
ferencia del flaneur, observador agudo de la ciudad y los hombres que la habitan, la paseante de los grandes almacenes no mirará personas sino objetos a la venta. Es novedosa la posesión visual, aún se puede ver sin expresar interés en comprar. Como diría Taine a propósito de la Exposición Universal de I855, las mujeres se desplazan "para ver mercancías»..$^{40}$ Las fronteras entre lo público y lo privado se hallan en plena redefinición. A las mujeres se les reserva un espacio doméstico que cada vez cumple menos funciones públicas, la arena política se despliega en los cafés y los clubes masculinos. La vida social aristocrática, el ritual de la visita y de la conjunción entre política, familia y economía, ceden espacio a una segmentación que deja a las mujeres en el lugar de mero decorado cuando les resulta posible trascender las fronteras del reducido espacio doméstico. ${ }^{4 \mathrm{I}}$

Atento al tedio de esa vida poco estimulante, Mouret hará de Au Bonheur des Dames un lugar donde pasar largas horas para las mujeres que tienen la subsistencia resuelta, pero a su vez no pueden resolver nada. Mientras la democratización política amplía las bases de la ciudadanía en clave masculina y las relativas mejoras materiales de la clase trabajadora recluyen a las mujeres en sus hogares, Au Bonheur des dames se yergue como un reducto público pensado especialmente para ellas. Ahí encuentran entretenimiento para sus hijos y se hace menos pesado el cuidado, ahí hallan las flores y los elogios que la monotonía del matrimonio no les proporciona. Escriben cartas, toman refrescos, socializan, presumen y chismorrean. La suma de atractivos que se concentra en los almacenes permite reemplazar todos los comercios por uno solo. Mas no contentos con ello, es necesario prolongar la estancia con espacios cómodos, lugares de descanso y hasta de reflexión, como el diseñado para escribir cartas,

40 Walter Benjamin, op. cit., p. 4I.

4I Philiphe ARIes y George Duby, Historia de la vida privada - Sociedad burguesa. Aspectos concretos de la vida privada, Madrid, Taurus, I99I, Tomo viII. 
refrescos y tentempiés, restaurantes, novedades y una anárquica sucesión de novedades que abrume la vista y obligue a recorrerlo todo.

La frontera entre lo público y lo privado se resignifica en los grandes almacenes, donde se puede fisgonear sin pedir permiso, tocar sin comprar y deambular a gusto. La tienda es un lugar privado en términos jurídicos, pero público en términos sociales. Un templo del hedonismo al que se puede acudir sin una razón, una línea de continuidad con el espacio propiamente público. Los jardines de su interior rememoran la plaza pública, las galerías interminables se asemejan a calles. Au Bonheur des dames irrumpe en el espacio público con el esplendor que azora a los paseantes y los invita a entrar. En otra premonición del siglo que se avecina, ${ }^{42}$ nos dice el narrador que, si hubiera estado en sus manos, Mouret habría hecho que la calle pasara por el medio de la tienda. Si la urbanización de Haussmann amenaza con la caída en desuso de los pasajes como confluencia entre el espacio privado y el público, en virtud de la reconfiguración de este último, ${ }^{43}$ el gran almacén exhibe la pretensión de integrarse hasta el punto de ser él mismo la ciudad. Debe reconocérsele a Zola alguna dosis de literatura de anticipación.

La tienda es el lugar donde las clientas pasan largas horas, pero aún lo es más para quienes trabajan en ella. Las fronteras entre lo público y lo privado se tornan borrosas en sentidos opuestos. Allí, los dependientes, muchos de ellos jóvenes y recién llegados, no sólo trabajan en jornadas muy prolongadas, sino que comen en espacios comunes, y al caer la noche duermen y se asean como pueden en cuartuchos que no replican el esplendor de los espacios visibles de la

42 "Otra» porque, al referirse a los beneficios que se gestan para los obreros en $A u$ bonheur des dames, señala "C'était l'embryon des vastes sociétés ouvrières du vingtième siècle». Émile Zola, op. cit., p. 742. Trad.: «Era éste el embrión de las grandes asociaciones obreras del siglo xx». Émile Zola, op. cit., p. 457.

43 Stephane Kirkland, Paris Reborn, Napoléon III, Baron Haussmann, and the Quest to Build a Modern City, Nueva York, St. Martin Press, 2014.

Cercles. Revista d'Història Cultural, 24 (2021), 13-46.

ISSN: 1139-0158. e-ISSN: 1699-7468. DOI: 10.1344/cercles2021.24.1001. 
tienda. Uno de los lugares comunes del proceso de industrialización radica en demarcar la separación entre trabajo y vida, construida por antinomia con los espacios rurales en que la producción, la reproducción y el consumo se desarrollan en zonas de cercana convivencia. ${ }^{44}$ El gran almacén con alojamiento incluido dejará escaso margen para el despliegue de una vida privada. Ese es un lujo burgués. En los cuartos compartidos y los pasillos por los que puede fisgonear cualquiera, todo resabio de intimidad se transforma en chisme. Mientras que las damas burguesas llegan a la tienda hartas del tedio doméstico, las dependientas no tienen ni un lugar decente donde llorar.

El gran almacén contiene, en la narrativa de Zola, todos los temores y utopías de la modernidad. A la vez templo de modernidad y monstruo que todo lo fagocita, en su descripción se hallan los aspectos más idealizados y los más distópicos sobre los tiempos que corren. El esplendor de la modernidad se despliega en descripciones que no escatiman en detalles. Se destaca el hierro, así como la heterodoxia del «joven arquitecto» que lo expone como parte de la decoración en lugar de ocultarlo con yeso. El sujeto que inspiró este personaje es nada más y nada menos que Gustave Eiffel. La torre que lleva su nombre se había inaugurado pocos años antes de la publicación de $A u$ Bonheur des dames. Él mismo había llevado a cabo la colosal reforma de Le Bon Marché, la gran tienda departamental en que se inspira Zola para su novela. ${ }^{45}$ No es extraño que destacara lo osado de la decisión arquitectónica, cuando la exposición del hierro todavía se consideraba de mal gusto. Benjamin diría más tarde que, con el hierro, la arquitectura comienza a desprenderse del arte. ${ }^{46} \mathrm{La}$

44 Marie-Agnès Barrère Maurisson, La división familiar del trabajo, Buenos Aires, Hvmanitas, 1999 .

45 Michael Miller, The Bon Marche. Bourgeois Culture and the Department Store. I869-I920, Nueva Jersey, Princeton University Press, I98I.

46 Walter Benjamin, op. cit.

Cercles. Revista d'Història Cultural, 24 (2021), 13-46. ISSN: 1139-0158. e-ISSN: 1699-7468. DOI: 10.1344/cercles2021.24.1001. 
masividad de su producción, duplicada en dos décadas, ${ }^{47}$ aproximaría acaso la arquitectura a la industria. Las tensiones entre modernidad y tradición en la estética y el consumo expresan las tensiones en el senode la transición de la sociedad aristocrática a la burguesa. Los antiguos privilegiados se resisten a las nuevas construcciones, al consumo masivo de la mano de una producción igualmente masiva. En suma, a todo aquello que esté reñido con la distinción que prometía estar ahora al alcance de todos, y por ello mismo desaparecer como tal. Valga recordar que el icono de París no se acogió gratamente en tiempos de su inauguración.

El esplendor se continúa con la exhibición cuidadosa y planificada de las telas, los vestidos, los accesorios:

Exposer le poème entier des vêtements de la femme. ${ }^{48}$

Poema barroco, por cierto, abundante en detalles y accesorios, que hace de la belle époque un momento privilegiado para el ramo en cuestión. El atuendo femenino completo es arduo, elaborado, complejo. Es improbable entrar en los grandes almacenes y salir de allí con un solo producto. El amplio espectro de rubros incluidos en la tienda aventaja al pequeño comercio no sólo por la facilidad de encontrar todos los productos en un mismo lugar, sino porque la exhibición puede ser más acabada y completa, puesto que, en ese poema entero, cada producto complementa al resto.

La tienda crece y fagocita con su esplendorosa presencia a los pequeños comercios que resisten hasta desfallecer. Uno a uno, Mouret va comprando los locales que la circundan hasta abarcar la manzana completa, con un ansia de despliegue que recuerda a las coetáneas poten-

47 Eric Новsваwм, op. cit., p. 43

48 Émile Zola, op. cit., p. 818. Trad.: "Cabía entero el poema del atuendo femenino». Émile Zola, op. cit., p. 503. 
cias imperiales. El gran comercio viene a completar el ciclo de expansión disparado por la gran industria. Si la escala de la producción ha cambiado, también debe hacerlo la del comercio. La escala cambia las reglas del juego, realza el protagonismo del intermediario, que merced a su poder de compra tiene en sus manos incluso a los productores. La esplendorosa ocupación del espacio se impone sobre la ciudad, hace inevitable la visita y en su interior ocurre el encanto. En el plano de la ciudad, la tienda se erige como el nuevo epicentro de la ciudad:

Audelà, Paris s'étendait, mais un Paris rapetissé, mangé par le monstre : les maisons, d'une humilité de chaumières dans le voisinage, s'éparpillaient ensuite en une poussière de cheminées indistinctes; les monuments semblaient fondre, à gauche deux traits pour Notre-Dame, à droite un accent circonflexe pour les Invalides, au fond le Panthéon, honteux et perdu, moins gros qu'une lentille ${ }^{49}$

Es posible trazar, en esta mirada panorámica de la ciudad, una continuidad discursiva en el interior de la obra de Zola, ${ }^{\circ}$ y también en diálogo con Víctor Hugo y Balzac, entre otros. ${ }^{5 I}$ En esa perspectiva que linda con la fotografía panorámica, ${ }^{52}$ Zola ve elevarse al gran almacén como epítome de la nueva París de Haussmann. ${ }^{53}$ La mo-

49 Émile Zola, op. cit., p. 817. Trad.: «Más allá, se extendía París, pero un París empequeñecido, que el monstruo engullía: las casas, modestas como chozas en sus proximidades, se dispersaban luego formando un confuso polvillo de chimeneas. Los monumentos parecían desvanecerse: dos trazos, a la izquierda, para Notre-Dame; un acento circunflejo a la derecha para los Inválidos; al fondo, el Panteón, perdido y vergonzante, más diminuto que una lenteja». Émile ZoLA, op. cit., pp. 502-503.

5o Juan Calatrava, «En los orígenes de la metrópolis moderna: Émile Zola y el París de Haussmann", en Juan Calatrava Escobar y José Antonio GonzÁlez Alcantud (eds.), La ciudad: paraíso y conflicto, Andalucía, Abada, 2007.

5I David Harvey, París. Capital de la modernidad, Madrid, Akal, 2006.

52 Walter Benjamin, op. cit.

53 Jean-Pierre Bernard, op. cit.

Cercles. Revista d'Història Cultural, 24 (2021), 13-46. ISSN: 1139-0158. e-ISSN: 1699-7468. DOI: 10.1344/cercles2021.24.1001. 
dernidad humilla a la antigua París, expresada en el Panteón. Au Bonheur des dames, más que estar en París, es París. ${ }^{54}$ El protagonismo del comercio no solo se impone sobre la ciudad, sino que literalmente, y más allá del eslogan publicitario, el viaje a la ciudad es el viaje a la tienda. Una de las grandes innovaciones de Le Bon Marche y la ficcional Au Bonheur des dames es, además de las dimensiones de la publicidad que llevan la presencia de la tienda más allá de sus límites físicos, la edición de catálogos de venta para cada temporada. La innovación atrae a la clientela a la tienda y al mismo tiempo hace posibles las ventas en el interior del país.55 El brillo desmedido encandila, más aún, enceguece. La majestuosidad del volumen atrae, luego, asusta. La desmesura de lo bello lo transforma en monstruoso. La tienda como monstruo, descrita en el fragmento antes citado, es recurrente en la novela. El crecimiento desmedido, "pareil à l'ogre des contes, dont les épaules menacent de faire craquer les nuages», ${ }^{56}$ se transmuta de esplendoroso en monstruoso. El monstruo devora a sus vecinos comerciantes, compitiendo hasta fundirlos y comprando sus locales; lleva por el camino de la perdición a las clientas, que se vuelven vanidosas y hasta ladronas; desgasta las energías vitales de los empleados, a quienes mastica y escupe a la calle cuando ya no queda nada útil por extraer.

El sentido común de lectores nos lleva a asociar el monstruo a alguna clase de ser vivo. Fealdad y maldad son sus cualidades definitorias. Au Bonheur des dames es un monstruo inanimado y bello. Esta clase de monstruo se parece más a algunos de los que nos ha

54 A partir de recuerdos confusos de algunos adultos cercanos, llega en forma de historia oral el eslogan de una famosa tienda de Buenos Aires. «Si pasa por [...], visite Buenos Aires». El protagonismo de la gran tienda como atracción urbana constituye una redefinición de lo público y lo privado. No son catedrales, museos ni paisajes, sino comercios.

55 Michael Miller,op. cit.

56 Émile Zola, op. cit., pp. 8I6-8I7. Trad.: «a semejanza de un ogro de cuento cuyos hombros amenazasen con horadar las nubes del cielo». Émile Zola, op. cit., p. 503.

Cercles. Revista d'Història Cultural, 24 (2021), 13-46.

ISSN: 1139-0158. e-ISSN: 1699-7468. DOI: 10.1344/cercles2021.24.1001. 
dado la ciencia ficción, como la máquina de Wells en El señor de los dinamos, hipnótica, divina y, al final, devoradora de la vida humana. Como la criatura de Frankenstein, la máquina y la tienda son creaciones humanas. A diferencia de este, son ideas individuales y construcciones colectivas. Son trabajo acumulado, es decir, capital. Producen fascinación por su potencia y sus magníficas dimensiones. La seducción del monstruo nos remite, más que al monstruo, al vampiro. Sensual, erótico. Su peligro radica en su belleza, en su capacidad seductora que nos lleva hacia el interior de sus fauces por voluntad propia. El atractivo hace que advirtamos el peligro demasiado tarde, cuando ya hemos vaciado nuestros bolsillos o escondido un par de guantes dentro del escote. Vale señalar que, si la moda de la belle époque daba literalmente mucha tela para cortar a los vendedores, también ofrecía abundancia de escondites a las ladronas.

Caben, asimismo, algunos reparos al carácter inanimado del monstruo. Si bien la tienda es un inmueble, la narración de Zola le confiere un dinamismo más bien propio de las máquinas, término del que también se vale de manera recurrente en referencia a la tienda. Funciona, retumba, se mueve. Al igual que con la ciudad, con el gran almacén opera la personificación. ${ }^{57}$ La máquina "a manger les femmes», ${ }^{58}$ a las clientas, $\mathrm{y}$ "écrasait le pauvre monde», ${ }^{59}$ los trabajadores. «El dínamo grande» de Wells,${ }^{60}$ el «monstruo mecánico» de Marx. ${ }^{61}$

57 Maarten van BuUren, op. cit.

58 Émile Zola, op. cit., p. I63. Trad.:«se tragaba a las mujeres». Émile Zola op. cit., p. 104 .

59 Émile Zola, op. cit., p. 486. Trad.:«aplastaba a los desventurados». Émile Zola, op. cit., p. 300.

60 H. G. Wells, «El señor de los dínamos», en Elvio Gandolfo (comp.), Los mejores cuentos de ciencia ficción. Cuando la imaginación se adelanta al tiempo, Buenos Aires, Ameghino, I998.

6I Karl Marx, El capital, Luarna, libro electrónico, tomo I, 2009 [I867], p. I.I3O. Disponible en: http://www.ataun.net/bibliotecagratuita/Clásicos\%2oen\%2oEspañol/Karl\%20 Marx/El\%2ocapital\%2oI.pdf (última visita: I2 de diciembre de 20I8). 
Au Bonheur des dames es monstruoso, es seductor, y también divino. El nuevo culto de la moda tiene allí su templo y sus fieles profanas son las damas que se pierden en sus corredores:

C'était la cathédrale du commerce moderne, solide et légère, faite pour un peuple de clientes. ${ }^{62}$

Si la moda es el culto y la tienda la catedral, la publicidad es su evangelio. Su esplendor atrae la vista de los paseantes, pero semejante templo no puede contentarse con las visitas casuales. Es necesario atraer allí al público mediante toda clase de argucias persuasivas:

Il professait que la femme est sans force contre la réclame, qu'elle finit fatalement par aller au bruit. ${ }^{63}$

Los engaños de la publicidad parecen haber desvelado a Zola, quien lleva al extremo las advertencias sobre sus efectos en «Una víctima de la publicidad», donde narra la historia de un pobre hombre cuya obediencia a los anuncios publicitarios lo conduce hasta una muerte miserable. La publicidad doblega las voluntades, y aún más, logra un prodigio propio de los dioses: la omnipresencia. La diversificación de estrategias publicitarias lleva a Au Bonheur des dames mucho más allá de sus fronteras materiales:

62 Émile Zola, op. cit., p. 490. Trad.: «Aquel edificio era la catedral del comercio moderno, resistente y airosa, construida para todo un pueblo de compradoras». Émile ZoLA, op. cit., p. 303.

63 Émile Zola, op. cit., p. 492. Trad.: «Mouret profesaba la teoría de que la mujer pierde las fuerzas ante la propaganda y acaba, fatalmente, por acudir a los lugares que dan que hablar». Émile ZoLA, op. cit., p. 305.

Cercles. Revista d'Història Cultural, 24 (2021), 13-46.

ISSN: 1139-0158. e-ISSN: 1699-7468. DOI: 10.1344/cercles2021.24.1001. 
C'était l'envahissement définitif des journaux, des murs, des oreilles du public, comme une monstrueuse trompette d'airain, qui, sans relâche, soufflait aux quatre coins de la terre le vacarme des grandes mises en vente. ${ }^{64}$

La publicidad es el zumbido en las mentes cuyos deseos deben despertar, el ingrediente secreto para que la ley de Say se haga carne y las clientas se descubran seducidas por el deseo irrefrenable de poseer algo cuya existencia ni tan siquiera conocían poco antes. Anuncios en periódicos, catálogos, rebajas, globos impresos en las manos de los niños, llegan a los ojos de la población como prédicas paganas del nuevo culto. El hechizo se completa cuando, habiendo sucumbido al poder persuasivo de la publicidad, se despliega en la tienda la exhibición obscena de toda clase de vanidades. El atractivo de los escaparates y la tienda dispuesta para que todo pueda verse y tocarse, aumentan el encanto. Otra innovación que resulta impúdica a ojos del comercio tradicional. Expuestos los productos y los precios, la tentación está más que servida. Si la mujer acude por lo necesario, acabará con lo superfluo, convencida de las encomiables ventajas de las falsas gangas.

La historia no cae, sin embargo, en el timo de la meritocracia del puro talento. Las ideas de Mouret y su espíritu arriesgado no valen de mucho sin un capital que arriesgar. En la figura del barón Hartmann encontramos un personaje de acotado protagonismo en la novela, pero fundamental para la concreción de los proyectos de la envergadura de Au Bonheur des dames. En el último cuarto del siglo XIX, Francia estaba experimentando un tardío —en contraste

64 Émile Zola, op. cit., p. 8I8. Trad.: «Había invadido de forma definitiva los periódicos, las paredes, los oídos del público, como una monstruosa trompeta de bronce que sonase sin tregua, enviando a los cuatro puntos cardinales el estruendo de las grandes ventas». Émile Zola, op. cit., p. 503. 
con el británico- proceso de financiarización de su economía. El Crédit Mobilier, fundado en I852 y en cuyo directorio se encuentra dicho personaje, ha sido identificado por los historiadores económicos como un actor fundamental para el despegue económico francés. A partir de él, Gerschenkron construyó su teoría sobre el atraso económico y la relevancia de los bancos, y luego del Estado, para favorecer los despegues tardíos. ${ }^{65}$ Hartmann, con la rentabilidad como nave insignia, no duda en diversificar sus inversiones, apostando en simultáneo a Au Bonheur des dames y a Las Cuatro Estaciones, su joven competidora. Es el capital financiero, en definitiva, lo que hace posible la expansión de la escala de la empresa. La catedral del comercio que rinde culto a la moda y tiene como fieles a las mujeres consumidoras funciona gracias al capital financiero como poderoso mecenas, trama económica sostenida a lo largo de toda la obra. ${ }^{66}$ Con todo, en este capítulo de la historia, reina el comercio. Au Bonheur des dames está tan atestado de tentaciones que casi se parece al infierno.

\section{Una última apostilla: The Paradise, una relectura británica en el siglo xxI}

La serie de la BBC, emitida entre 2012 y 20I3, lleva la historia parisina a Londres. Unas cuantas complejidades de la historia se disuelven en la versión televisiva, al tiempo que se incorporan guiños feministas fruto de una lectura y una narrativa propias dl siglo xxI. Sin embargo, algunas complejidades eliminadas contribuirían aún más que la versión original a la construcción de un estereotipo femenino he-

65 Charles Kindleberger, Historia financiera de Europa, Barcelona, Crítica. 20II, p. 149.

66 Henri Mitterand, Dictionnaire de grandes oeuvres des litterature françoise, París, Le Robert, 1992.

Cercles. Revista d'Història Cultural, 24 (2021), 13-46.

ISSN: 1139-0158. e-ISSN: 1699-7468. DOI: 10.1344/cercles2021.24.1001. 
gemónico. La Denise de The Paradise, para empezar, está despojada de sus hermanos y la carga emocional y económica que ello implica. Llega sola a Londres y ello ya la convierte, de por sí, en menos pobre y más atractiva que la Denise original. Aunque sus botas están igual de rotas y posee apenas más que lo puesto, su belleza sin fisuras resulta llamativa aún bajo los trapos viejos y confiere inverosimilitud a las recurrentes llamadas de atención de la señora Audrey por su aspecto desaliñado. La figura de Henriette es reemplazada por Katherine Glendenning, quien no es viuda, sino huérfana de madre, y en lugar de rondar los cuarenta es una joven apenas mayor que Denise. Tan delgada y esbelta como ella, mas de cabellos y ojos castaños, nos recuerda que en la mente de un novelista del siglo XIX entraban más formas posibles de ser mujer que en la televisión masiva del siglo XxI. Una mujer de cuarenta y algo entrada en carnes no pasa el casting. Esta homogeneización se redime con prudente moderación en el personaje de Pauline, cuya protagonista, de más baja estatura y rasgos menos coincidentes con la norma imperante, aunque igualmente delgada, cumple un rol semejante al propuesto en la novela. De hecho, su intérprete, Ruby Bentall, ha sido una voz crítica de la hegemonía y estandarización de "lo bello», y añade que aún se la pretende encasillar en determinados papeles en virtud de su aspecto físico. ${ }^{67}$

La reescritura de la historia transforma el final feliz decimonónico de la boda en algo más semejante al sueño americano. Denise, construida como un personaje no sólo con ideas propias — como en la novela-, sino también con grandes ansias de éxito y reconocimiento, propone a Moray (Mouret) postergar la boda hasta que haya logrado establecerse con su propia empresa. A la Denise del siglo XXI no le alcanza — no debe alcanzarle — con volver a París

67 «I work in an industry obsessed with looks», BBC Sport, 20 de enero de 2016. Disponible en: https://www.bbc.co.uk/sport/av/bodypositive/35360606 (última visita: 8 de diciembre de 2018). 
del brazo de Mouret. Mas tampoco debería prescindir de ello. A la belleza impecable y el matrimonio exitoso, se le suma el mandato del éxito profesional. Feminismo hollywoodense poco amigo de la diversidad. Ese ideal al que, en palabras de Virgine Despentes, resulta tan hegemónico como inexistente:

[...] el ideal de la mujer blanca, seductora pero no puta, bien casada pero no a la sombra, que trabaja pero sin demasiado éxito para no aplastar a su hombre, delgada pero no obsesionada con la alimentación, que parece indefinidamente joven pero sin dejarse desfigurar por la cirugía estética, madre realizada pero no desbordada por los pañales y por las tareas del colegio, buen ama de casa pero no sirvienta, cultivada pero menos que un hombre, esta mujer blanca feliz que nos ponen delante de los ojos, esa a la que deberíamos hacer el esfuerzo de parecernos, aparte del hecho de que parece romperse la crisma por poca cosa, nunca me la he encontrado en ninguna parte. Es posible incluso que no exista. ${ }^{68}$

Este pretendido feminismo marquetinero, blanco, burgués, tan presente en la cinematografía contemporánea como en sus intérpretes, otorga especificidad femenina a ese ideal burgués que, como nos advierte Romanelli, ${ }^{69}$ presenta escasas pruebas documentales en la Europa decimonónica.

No sería justo, sin embargo, insistir en que la serie sea tan chata y gris. Otros aspectos de la historia lucen con mayor esplendor. La originalidad de las ideas comerciales de Moray (Mouret) y luego de Denise; la expansión del comercio de lo superfluo, de la necesidad al deseo como móvil del consumo; las mujeres y los niños como nichos específicos del mercado; la relevancia del capital financiero, así como la decadencia del comercio tradicional, tienen un lugar protagónico en la historia. Otros vericuetos que difieren de la versión original nos

68 Virginie Despentes, Teoría de King-Kong, Madrid, Melusina, 2007, pp. IO-II.

69 Raffaele Romanelli, , op. cit., pp. I-24. 
alejarían demasiado del contrapunto con $A u$ bonheur des dames. Quizás los aspectos menos divergentes son aquellos en que la continuidad predomina sobre la ruptura entre los tiempos de Zola y los nuestros. La masificación del consumo, el poder de la publicidad, la representación de la mujer como consumidora. En el siglo XXI, los paseos comerciales se nos figuran como paraísos - e infiernos- replicados en cualquier lugar del mundo. El aspecto de las modelos que lucen las prendas se parece tanto como lo que llevan puesto y, si apareciéramos perdidos en el interior de uno de ellos, tal vez nos costaría adivinar a qué ciudad del mundo hemos sido arrojados. El imposible en la novela de Zola, relatado casi como un delirio, de hacer pasar la calle por el medio de los almacenes se ha materializado en los paseos comerciales de los siglos Xx y XxI alrededor del mundo. Su originalidad se ha vuelto canónica. En este sentido, vale el esfuerzo de reconstruir como narrativa de la novedad aquello que se ha vuelto parte del aire que respiramos en la vida posmoderna. Como ocurre a menudo con éxitos cinematográficos y televisivos, hubo una oportuna reedición en inglés, con un fotograma de la serie como ilustración de portada. ${ }^{70}$ Aunque el rostro en primera plana de la actriz protagonista de la serie quizás constriña el modo de acercamiento a la creación de Zola, permite leer por primera vez una obra que, como todo clásico, diría Calvino, solemos asumir solo como relectura. ${ }^{71}$

\section{Conclusiones}

Cuando se publica $A u$ Bonheur des dames, el hervidero de transformaciones retratadas en Les Rougon-Macquart está sedimentando.

70 Émile Zola, The Paradise. A novel, Nueva York, Penguin Books, 2013. Trad.: Ernest A. Vizzitelly.

7I Italo Calvino, Por qué leer clásicos, Barcelona, Tusquets, 1992. 
Narra la historia de un ciclo cerrado —el Segundo Imperio y la París de Haussmann-, pero vivo en los cambios que llegaron para quedarse. Zola ficcionaliza una historia de su tiempo presente. La circulación y trascendencia de su obra, en diálogo con los objetivos de su proyecto artístico ${ }^{72}$ permiten intuir que esas representaciones trascienden la individualidad. Au Bonheur des dames nos habla de un mundo en que las fronteras entre lo público y lo privado se hallan en plena redefinición. Para las mujeres se está construyendo un reinado doméstico al tiempo que se las excluye de la política y se las segrega a roles subalternos en la producción. La historia de Denise podría leerse a la ligera como la de cualquier heroína del amor folletinesco. Pero Au Bonheur des dames es mucho más que una historia de amor interclasista. De hecho, si tuviéramos que recurrir a algún criterio de representatividad estadística, las carencias materiales, el consumo, el lujo, la expansión económica y la decadencia de viejas prácticas comerciales tienen muchas más palabras dedicadas que la historia de amor entre Denise y Mouret. Incluso entre ellos, hablan más de las posibilidades del negocio y los derechos laborales que de su propio amor. El final feliz de la boda, como es de esperar en el género, tiene apenas un anticipo. El matrimonio burgués es muy monótono para inspirar obras literarias en el siglo xix. Acaso porque la felicidad obligada es el ingreso en la norma. El «amor civilizado», si se me permite el anacronismo sabinesco, desborda las fronteras del interés literario.

Todo ello es, ya se ha dicho, una lectura poco enfocada que encuentra en el texto el cliché de la chica pobre que acaba enamorando al hombre rico (y enamorándose de él) y deja una rendija de esperanza a las miles de Denises que trabajan para vivir, o al menos para no

72 Yves Lochard, «Novela naturalista y formación de los imaginarios urbanos: el ejemplo de París y sus afueras a fines del siglo XIX», Figuraciones. Teoría y crítica de las artes, núm. I-2, 2003.

Cercles. Revista d'Història Cultural, 24 (2021), 13-46.

ISSN: 1139-0158. e-ISSN: 1699-7468. DOI: 10.1344/cercles2021.24.1001. 
morir. Pero Au Bonheur des dames es, insisto, mucho más que literatura de consolación. ${ }^{73}$ El protagonismo de la tienda como espacio físico y como actor económico atraviesa la existencia de todos los personajes. Elevada a imagen y semejanza del demiurgo Mouret, la tienda se va erigiendo como su obra, su razón de ser, su imperio. Parafraseando a Martín Santos, Mouret es la imagen de Au Bonheur des dames y Au Bonheur des dames las vísceras puestas al revés de Mouret. ${ }^{74}$

París y Mouret. Zola y París. En ellos se resume la utopía del progreso. No sólo en cada uno por separado, sino en ambos como díada. En este sentido, la figura de Denise resulta trascendental. Completa a Mouret con su creatividad y sensibilidad dirigidas a mejorar el comercio y las condiciones de trabajo de los empleados. De tercera en discordia pasa a integrarse a una tríada que, si nos ofrece alguna consolación, es más compleja que la mera movilidad social a la que puede aspirarse por el matrimonio burgués. En Au Bonheur des dames no sólo se enriquece Denise, sino que el amor de ambos devuelve una imagen mejorada del mundo, que es la tienda. El monstruo se transforma en catedral del progreso y el conocimiento. Los empleados cuentan con atención médica, educación, biblioteca, salones de juegos. En el camino contrario del monstruo creado por Frankenstein, cuya crueldad se explica por su desdicha, ${ }^{75}$ Mouret y Au Bonheur des dames reciben amor en la figura de Denise y la dicha los hace buenos. El Estado social forja una experiencia primigenia a la luz del amor entre la proletaria y el burgués. En este sentido, como el propio Zola reivindica, Au Bonheur des dames es una ventana al siglo xx. Al menos, al siglo xx que hombres como Zola imaginaban en 1883 . Si, como

73 Beatriz SARlo, El imperio de los sentimientos, Buenos Aires, Norma, 2004.

74 «Un hombre es la imagen de la ciudad y la ciudad las vísceras puestas al revés de un hombre». Luis Martín Santos, Tiempo de silencio, Madrid, Seix-Barral, 1962, p. I2.

75 Isabel BuRDIEL, «Lo imaginado como materia interpretativa para la historia. A propósito del monstruo de Frankenstein", en I. Burdiel, y J. Serna, Literatura e historia cultural, Valencia, Episteme, 1996. 
dijera Paul Valery, «el futuro ya no es lo que solía ser», la lectura de A Bonheur des dames nos ofrece un prisma entre tantos para ver la París que Zola vio, pero también el «futuro pasado» ${ }^{76}$ que se gestó al calor de las metamorfosis sociales y urbanas de las que fue contemporáneo.

76 Reninhart Koselleck, Futuro pasado. Para una semántica de los tiempos históricos, Barcelona, Paidós, 1993.

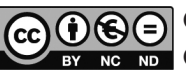

Copyright (C) 202I. Aquesta obra està subjecta a una llicència de Creative Commons mitjançant la qual qualsevol explotació n'haurà de reconèixer els autors, citats a la referència que apareix a l'inici del document.

Cercles. Revista d'Història Cultural, 24 (2021), 13-46.

ISSN: 1139-0158. e-ISSN: 1699-7468. DOI: 10.1344/cercles2021.24.1001. 